\title{
Análise estrutural do pensamento normativo e contranormativo de conselheiros municipais do idoso sobre a preparação para velhice
}

Janaína da Silva Gonçalves Fernandes. Centro Universitário FIEO.

Márcia Siqueira de Andrade. Centro Universitário FIEO.

\section{Resumo}

O objetivo desta pesquisa foi identificar como se organizam as representações sociais e elementos que indicam uma zona muda de conselheiros municipais do idoso sobre preparação para velhice. Participaram 72 integrantes de Conselhos Municipais de Direitos do Idoso de seis municípios da grande São Paulo. Para coleta de dados utilizou-se Técnica de Evocação Livre de Palavras hierarquizada em situações de coleta normal e de substituição, a partir do termo indutor "preparação para velhice". Os dados foram analisados pela Análise Prototípica, com apoio do software IRAMUTEQ. Confirmou-se centralidade do elemento "saúde" na situação normal e na situação de substituição o mesmo foi considerado elemento periférico sobre ativado. Na periferia comum destacou-se possibilidade de zona muda que não aceita e não reconhece o próprio envelhecimento. Considerou-se existência de estereótipos negativos relacionados à velhice.

Palavras chave: idosos; políticas públicas; representação social; velhice.

\begin{abstract}
Structural analysis of thought normative and against normative of municipal counselors of elderly about the preparation for old age. The objective of this research was to identify how to organize social representations and elements that indicate silent zone of municipal counselors of elderly about preparation for old age. Seventy-two members of Municipal Councils for the Rights of the Elderly participated in six municipalities in the greater São Paulo. To collect data, we used a Word-Free Evocation Technique hierarchized in situations of collection normal and substitution, from the term inducer "preparation for old age". The data were analyzed by Prototypic Analysis, with support of IRAMUTEQ software. Centrality of element "health" was confirmed in normal situation and in the substitution situation same was considered peripheral element on activated. In common periphery it was highlighted possibility of silent zone that does not accept and does not recognize the aging itself. It was considered existence of negative stereotypes related to old age.
\end{abstract}

Keywords: elderly; public policie; social representation; old age.

\section{Resumen}

Análisis estructural del pensamiento normativo y contra normativo de consejeros municipales de adultos mayores sobre preparación para vejez. El objetivo esta investigación fue identificar cómo se organizan representaciones sociales y elementos que indican zona muda de consejeros municipales del anciano sobre preparación para la vejez. Participaron 72 integrantes de Consejos Municipales de Derechos del Anciano de seis municipios de la gran São Paulo. Para la recolección de datos se utilizó la técnica de Evocación Libre de Palabras jerarquizada en el situación normal y sustitución, a partir del término inductor "preparación para la vejez". Los datos adjuntos analizados por Análisis Prototípico, con apoyo software IRAMUTEQ. Se confirmó centralidad del elemento "salud" en situación normal y de sustitución el mismo fue considerado elemento periférico sobre activado. En periferia común se destacó posibilidad de zona que no acepta y en el propio envejecimiento. Se consideró existencia de estereotipos negativos relacionados con vejez.

Palabras clave: adultos mayores; políticas públicas; representación social; vejez. 
A fase da velhice envolve diversas e complexas variáveis, caracterizadas por mudanças físicas, cognitivas e psicossociais, que não ocorrem de modo simultâneo (Fernandes, Costa, \& Andrade, 2017; Torres, Camargo, Boulsfield, \& Silva, 2015). Neste sentido, a questão da preparação para velhice é aqui entendida como atitudes e ações adotadas tanto no plano individual quanto social, que buscam preservar as condições de um envelhecimento ativo, isto é, políticas públicas e planejamentos individuais que favoreçam a independência, saúde e autonomia dos idosos (World Health Organization [WHO], 2005).

Aird e Buys (2015) colocam que a preparação para velhice está relacionada às escolhas que os indivíduos fazem mais cedo na vida, por exemplo, em termos de poupança para comprar uma casa e aposentadoria. Posteriormente, estas escolhas terão um impacto sobre a segurança e bem-estar biopsicossocial do indivíduo. Assim, apontam a necessidade de se educar as gerações mais jovens sobre a importância de preparar-se para a fase da velhice.

A partir de pesquisa realizada na China, Lee e Xiao (1998) discutem sobre a problemática de crianças com pais idosos. Neste contexto, os pais utilizam a estratégia de colocar o sucesso da criança na principal preocupação familiar. Para isto, investem financeiramente na educação dos filhos, a fim de garantir a gratidão destes filhos e posteriormente um retorno deste investimento em suas idades avançadas, ou seja, se preparam para depender financeiramente dos filhos.

Outros estudos apontam que o envelhecimento acelerado da população acarreta o envelhecimento da força de trabalho, o crescimento da saída precoce do ambiente de trabalho, e a preocupação de assegurar finanças públicas sustentáveis (Fernandes \& Andrade, 2016; Freitas, Campos, \& Gil, 2017; J. O. Moreira, \& Vieira, 2014). As soluções discutidas frente a estas questões são: prolongamento da vida laboral ativa, promoção de políticas de igualdade de tratamento e redução dos custos de previdência social (Braconier, 2010; Fernández-Ballesteros, Robine, Walker, \& Kalache, 2013; Hinrichs, 2016).

Zaidi (2008) identifica cinco áreas de políticas públicas que são importantes para a inclusão efetiva dos idosos no contexto de trabalho e no incentivo da preparação da sociedade para o envelhecimento: políticas de pensões; de saúde e cuidados em longo prazo; de emprego; de migração e integração; e de infraestrutura e desenvolvimento. Neste sentido, considera-se relevante identificar o que pensam sobre a preparação para velhice, os atores atuantes nos Conselhos Municipais de Direitos do Idoso (CMDIs). Cabe aos integrantes destes conselhos, como formuladores de políticas públicas, na prática, submeter, opinar, discutir, debater e decidir, por meio de seu voto, assuntos relacionados aos direitos do público idoso.

Teoricamente, o conjunto de explicações, crenças e ideias comuns a um determinado grupo de indivíduos que representa um objeto são construídos histórica e socialmente e denominam-se representações sociais (Moscovici, 2012). A abordagem estrutural trata de uma perspectiva tal qual proposta por Abric (2001), que compreende as representações sociais como estruturas de conhecimento sobre ideias compartilhadas socialmente por grupos e construídas por elementos cognitivos conectados entre si. Sua principal abordagem é a teoria do núcleo central, que apresenta as representações sociais como um duplo sistema formado por um núcleo central e um sistema periférico.

O núcleo central é composto por elementos intensamente compartilhados pelo grupo, os quais explicam o significado da representação social e a organiza. Enquanto que o sistema periférico envolve a maioria dos elementos da representação, os quais apresentam uma natureza que suporta a heterogeneidade do grupo, de caráter flexível e prático, uma vez que são capazes de adaptar a representação às experiências e histórias individuais (Abric, 2001). De tal modo, nesta dinâmica que produz sentidos no campo individual e introduzem novos sentidos nos contextos sócios culturais, os aspectos ligados à preparação para velhice podem apresentar novos significados que ampliem a necessidade de aceitação do processo do envelhecimento no âmbito individual para a dimensão social.

Nesse sentido, a efetivação deste estudo torna-se relevante pela necessidade de compreensão do fenômeno relacionado ao envelhecimento populacional, considerando as dimensões social e simbólica da fase da velhice, a partir da verificação de elementos e saberes presentes na memória social. Assim sendo, o objetivo desta pesquisa é identificar como se organizam as representações sociais e os possíveis elementos que compõem a zona muda de conselheiros municipais do idoso sobre a preparação para velhice.

\section{Método}

\section{Participantes}

A pesquisa foi de abordagem mista, com delineamento descritivo exploratório, pautada na abordagem estrutural das representações sociais. A pesquisa foi proposta para ser realizada com 143 conselheiros distribuídos em CMDIs localizados em seis municípios da região oeste da grande São Paulo. Porém, foi possível contatar durante 
reuniões plenárias e obter a concordância de 72 conseIheiros, para a realização da pesquisa. Portanto, o estudo contou com uma amostra de conveniência, não probabilística, formada por 72 conselheiros com idade entre 20 e 80 anos, sendo 44 membros titulares e 28 membros suplentes. Esta seleção justifica-se devido ao fato dos conselheiros possuírem outras atribuições, além do CMDI, o que ocasionava escassa disponibilidade de horário para participação dos mesmos nas reuniões plenárias.

\section{Instrumentos e Procedimentos de Coleta de Dados}

O projeto foi aprovado pelo Comitê de Ética em Pesquisa da Instituição promotora. Inicialmente foi realizado contato prévio com os presidentes dos CMDIs para solicitação de autorização para realização da pesquisa. Esta autorização, em alguns casos, dependeu da aprovação de comissões auxiliares específicas dos CMDIs. Após estes procedimentos, a coleta de dados ocorreu em três momentos, de modo coletivo, durante reunião plenária dos CMDIs. No primeiro momento foi aplicada pela própria pesquisadora a Técnica de Evocação Livre de Palavras a partir do termo indutor "preparação para velhice" (escrevam cinco palavras que lhes vêm à mente).

No segundo momento, os participantes foram orientados a evocarem novamente cinco palavras, mas desta vez em situação de substituição, ou seja, foi dada a consigna: o que você acha que as pessoas de um modo geral pensam sobre preparação para velhice. Essa técnica propõe a isenção do indivíduo de ser julgado por expressar ideias não aceitas socialmente ou que o coloquem em constrangimento perante os valores seguidos por seu grupo de pertença. O controle ou mascaramento, de possíveis conteúdos não expressados, não é possível nesta segunda situação, pois se intenciona provocar uma articulação que diminua a pressão regulatória, presentes em contextos sociais normativos, que poderia inibir a fala dos participantes (Flament, Guimelli, \& Abric, 2006; Pena, Urdapilleta, Tavani, Pruzina, \& Verhiac, 2016).

Por último, foi solicitado que os participantes hierarquizassem, por grau de importância, as palavras ou expressões evocadas anteriormente. Essa técnica combinada aproveita os dados evocados a partir da evocação livre e o organiza cognitivamente, permitindo uma reavaliação da ordem de evocação. Esse procedimento contribui para o estabelecimento de uma hipótese de centralidade dos elementos evocados.

\section{Procedimentos de Análise de Dados}

Para análise foram considerados os dados hierarquizados pelos participantes, por grau de importância, das palavras ou expressões evocadas. Na sequência a análise dos dados obedeceu a seguinte ordem:

1. Lematização pelo radical: consiste em agrupar palavras ou expressões com radical léxico semeIhante para evitar maior dispersão, prevalecendo o modo singular, de maior frequência ou pelo verbo correspondente, como por exemplo, as palavras envelhecimento - envelhecendo - envelhecemos, foram lematizadas e agrupadas na palavra enveIhecer. Esta estratégia é efetuada homogeneizando o conteúdo semântico semelhante e sem alterar o sentido essencial da palavra ou expressão (Wachelke, 2009; Wachelke \& Wolter, 2011).

2. Análise prototípica: essa técnica apresenta a construção de quatro quadrantes que irão indicar as possíveis palavras que ocupam a centralidade na estrutura das representações sociais (Wachelke $\&$ Wolter, 2011). Para isto utilizou-se como apoio o software Interface de R pour analyses Multidimensionnelles de Textes et de Questionnaires (IRAMUTEQ) (Camargo \& Justo, 2016).

3. Índice de Centralidade de Representações Sociais a partir de Evocações (INCEV): realizado após análise prototípica avalia a centralidade de elementos representacionais considerando sua frequência, incondicionalidade e importância (Wachelke, 2009). A confirmação da centralidade é necessária nos estudos da abordagem estrutural, pois nem sempre os elementos apontados como pertencentes ao núcleo central na tarefa de evocação livre de palavras podem sê-lo realmente (Costa, Oliveira, \& Formozo, 2012).

\section{Resultados}

\section{Abordagem Estrutural sobre Preparação para Velhice}

As respostas evocadas e hierarquizadas por grau de importância pelos participantes, a partir do termo indutor "preparação para velhice" em situações normal e de substituição, constituíram dois corpus iniciais do material a ser analisado. Após lematização pelo radical léxico (tratamento de equivalência), cada corpus foi inserido separadamente no software IRAMUTEQ para a construção dos quadrantes apresentados em quatro casas (análise prototípica). Utilizou-se o critério das medianas para determinar os pontos de corte e determinar a distribuição das palavras evocadas nos quadrantes. Como foram coletadas cinco respostas por participante, o valor do ponto de corte foi 3 (Wachelke, \& Wolter, 2011). 
Na situação de coleta de dados normal, houve no total, 360 evocações. Após lematização pelo radical identificou-se 169 palavras diferentes e frequência média de 2,13. Identificou-se a frequência de 113 hapax, logo o índice de diversidade calculado corresponde a 0,46 e o índice de raridade de 0,66. Estes dados foram submetidos à análise prototípica resultando em 37 palavras diferentes (frequência igual ou acima de 3). A ordem média das evocações (OME) foi 2,90 e a frequência média $(F m)$ igual a 5,49 . A partir dos dados examinados nas situações de coleta normal verificou-se a existência de representações estruturadas (Flament \& Rouquette, 2003; Wolter \& Wachelke, 2013). A Tabela 1 apresenta os resultados da análise prototípica referente ao termo indutor "preparação para velhice" coletada em situação normal.

Tabela 1. Análise Prototípica Referente ao Termo Indutor "Preparação para Velhice" Coletada em Situação de Normal ( $\mathrm{N}=72)$.

\begin{tabular}{|c|c|c|c|c|c|c|}
\hline & \multicolumn{3}{|c|}{ Ordem média de evocações $\leq 2.90$} & \multicolumn{3}{|c|}{ Ordem média de evocações > 2.90} \\
\hline & Termo evocado & Frequência & $\begin{array}{l}\text { Ordem de } \\
\text { importância }\end{array}$ & Termo evocado & Frequência & $\begin{array}{c}\text { Ordem de } \\
\text { importância }\end{array}$ \\
\hline & Elementos centrais & & & $\begin{array}{c}\text { Elementos da } 1^{a} \\
\text { periferia }\end{array}$ & & \\
\hline \multirow{6}{*}{$\begin{array}{l}\text { Frequência média } \\
\qquad 5.49\end{array}$} & Saúde & 23 & 2.0 & Família & 20 & 3.2 \\
\hline & Despreparo & 8 & 2.5 & Atividade & 12 & 3.2 \\
\hline & Qualidade de vida & 8 & 2.6 & Financeiro & 8 & 3.5 \\
\hline & Alimentação & 7 & 2.7 & Cuidado & 7 & 4.0 \\
\hline & Aceitação & 6 & 1.8 & Lazer & 6 & 4.2 \\
\hline & Educação & 6 & 2.5 & & & \\
\hline \multirow{16}{*}{$\begin{array}{l}\text { Frequência média } \\
<5.49\end{array}$} & $\begin{array}{l}\text { Elementos de } \\
\text { contraste }\end{array}$ & & & $\begin{array}{c}\text { Elementos da } 2^{\mathrm{a}} \\
\text { periferia }\end{array}$ & & \\
\hline & Informação & 5 & 2.0 & Assistência & 4 & 3.0 \\
\hline & Conhecimento & 4 & 2.5 & Alegria & 4 & 3.5 \\
\hline & Doença & 4 & 2.5 & Respeito & 4 & 4.0 \\
\hline & Médico & 4 & 2.0 & Exercício & 4 & 3.2 \\
\hline & Amor & 4 & 2.2 & Limitação & 4 & 3.5 \\
\hline & Preparação & 4 & 2.2 & Prevenção & 4 & 3.0 \\
\hline & Falta & 4 & 2.8 & Esporte & 3 & 4.3 \\
\hline & Psicológico & 3 & 1.3 & Sociedade & 3 & 3.7 \\
\hline & Convivência & 3 & 2.7 & Cultura & 3 & 3.7 \\
\hline & Praticar & 3 & 2.0 & Frequentar & 3 & 3.0 \\
\hline & Ajuda & 3 & 2.7 & Participação & 3 & 3.0 \\
\hline & & & & Orientação & 3 & 3.7 \\
\hline & & & & Direito & 3 & 4.0 \\
\hline & & & & Realização & 3 & 3.7 \\
\hline & & & & Palestras & 3 & 4.0 \\
\hline
\end{tabular}

A partir dos resultados das evocações livres de palavras apresentados na Tabela 1 é possível compreender como se organizam as representações sociais dos participantes da pesquisa sobre a preparação para velhice na situação de coleta de dados normal. No primeiro quadrante superior esquerdo, podem-se observar os elementos que tiveram maior predominância na evocação dos participantes e fazem parte de um provável núcleo central das representações sociais do termo indutor.

Na situação de coleta de dados normal o elemento "saúde" apresentou maior frequência no primeiro quadrante superior esquerdo e os elementos "alimentação" e "qualidade de vida" apresentaram maior ordem de importância. No quadrante superior direito, constituem a periferia próxima das representações e referem-se à assimilação de novos conceitos, ainda não totalmente incorporados ao núcleo central, mas indicando uma possibilidade de inovação das crenças e opiniões. Os elementos mais frequentes da $1^{a}$ periferia são "família" e "atividade", e os elementos "lazer" e "cuidado" apresentaram a maior ordem de importância. O quadrante inferior esquerdo, também denominado de contraste, é composto de elementos que tiveram baixa frequência de evocação, mas que foram considerados importantes, pois foram prontamente evocados. Neste quadrante, o elemento mais frequente foi "informação", mas por ordem de importância foi "falta". No quadrante inferior direito, podem ser encontrados os elementos mais distantes do provável eixo central das representações sociais. Neste quadrante, houve maiores frequências em vários 
elementos, mas o que apresentou maior ordem de importância foi "esporte".

Em relação aos dados coletados em situação de substituição, também ocorreram no total, 360 evocações. Após lematização pelo radical identificou-se 157 palavras diferentes e frequência média de 2,29. Identificou-se a frequência de 102 hapax, logo o índice de diversidade calculado corresponde a 0,43 e o índice de raridade de 0,64. Estes dados foram submetidos à análise prototípica resultando em 34 palavras diferentes (frequência igual ou acima de 3). A ordem média das evocações (OME) foi 2,85 e a frequência média $(\mathrm{Fm})$ igual a 6,32. Também foi possível identificar a existência de representações estruturadas na situação de substituição (Flament \& Rouquette, 2003; Wolter \& Wachelke, 2013). A Tabela 2 apresenta os resultados da análise prototípica referente ao termo indutor "Preparação para velhice" coletada em situação de substituição.

Tabela 2. Análise Prototípica Referente ao Termo indutor "Preparação para Velhice" Coletada em Situação de Substituição ( $N=72$ ).

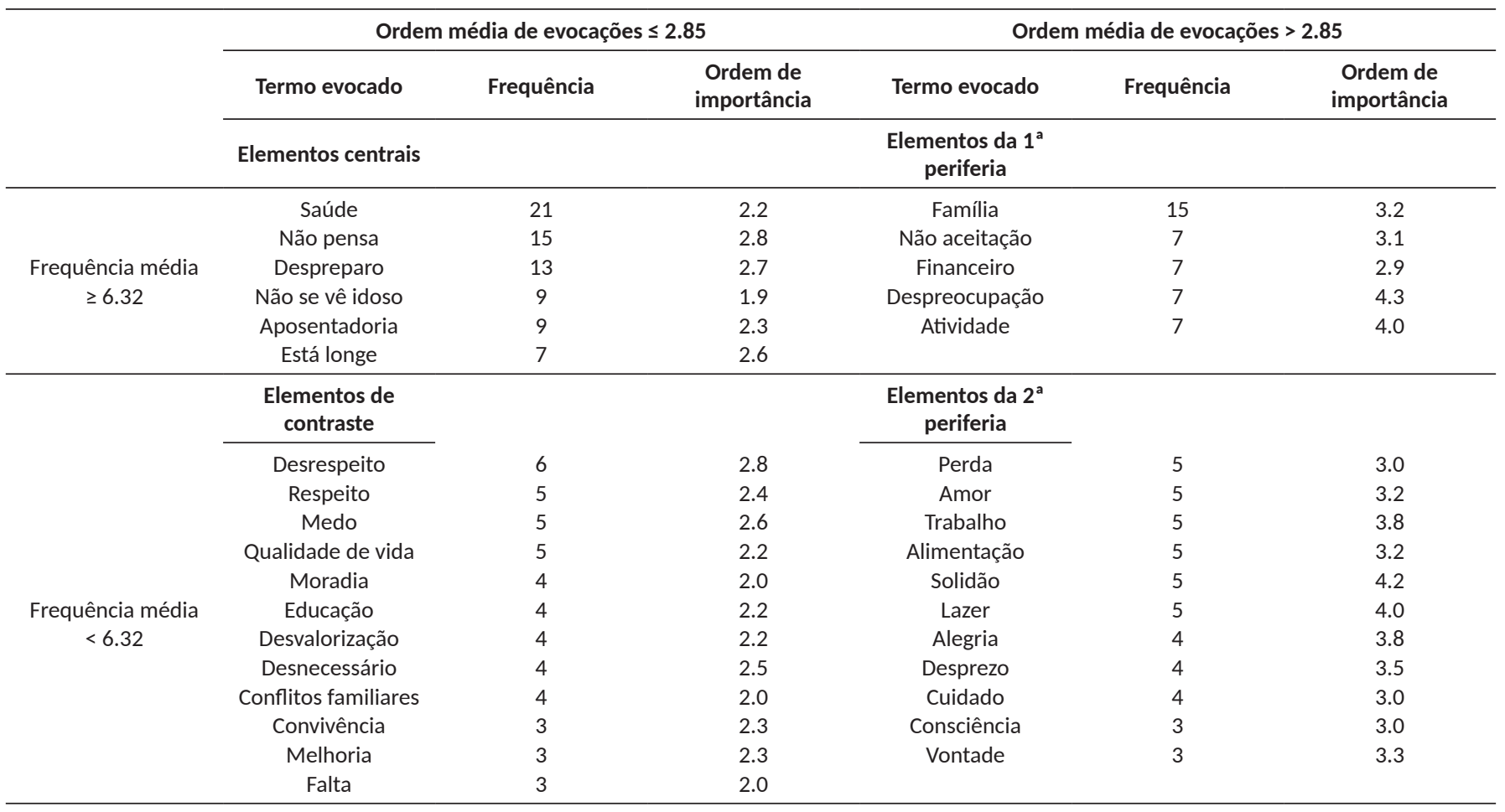

Nota. Elaborada a partir dos resultados do software IRaMuTeQ.

O elemento "saúde" assim como na situação normal novamente apresenta maior frequência na situação de substituição no primeiro quadrante superior esquerdo, mas diferiu-se na ordem de importância a partir da expressão "não pensa". O quadrante superior direito, também apresentou o elemento "família" como mais frequente na $1^{\text {a }}$ periferia, mas desta vez diferente da situação normal o elemento "despreocupação" apresentou maior ordem de importância. No quadrante inferior esquerdo, diferente da situação normal o elemento "desrespeito" apresentou maior frequência e ordem de importância. No quadrante inferior direito, houve maiores frequências em vários elementos, mas o que apresentou maior ordem de importância foi "solidão".

\section{Índice de Centralidade de Representações Sociais a partir de Evocações (INCEV)}

Para o cálculo do INCEV foi utilizado o critério de frequência total $\left(F_{T}\right)$, que estabelece incluir na análise uma proporção mínima de $5 \%$ das evocações dos participantes da amostra. No caso do presente estudo, a partir do percentual da amostra de 72 participantes, isso se deu a partir da frequência 3,6. Logo, a frequência mínima considerada foi de 4 , pouco mais de $5 \%$ do tamanho da amostra (Wachelke, 2009; Wachelke \& Wolter, 2011). As palavras resultantes foram agrupadas do seguinte modo:

Situação normal: a palavra "atividade" integrou-se com a palavra "exercício". A palavra "preparação" integrou-se a "prevenção". O elemento "educação" incorporou as 
palavras "informação", e "conhecimento". As palavras alimentação, lazer, assistência, respeito, e limitação foram excluídas, por não ser possível integrar a sinônimos correspondentes e também por não apresentarem ordem de evocação de alto valor simbólico (evocadas em primeiro lugar). As demais palavras assumiram o seu campo semântico correspondente de forma individual.

Situação de substituição: a expressão "não aceitação" integrou-se a expressão "não se vê idoso". o elemento "despreocupação" incorporou as expressões "está longe", "não pensa" e "desnecessário". O elemento "desvalorização" incorporou as palavras "desrespeito" e "desprezo". As palavras atividade, alimentação, solidão, lazer, e alegria foram excluídas, por não ser possível integrar a sinônimos correspondentes e também por não apresentarem ordem de evocação de alto valor simbólico (evocadas em primeiro lugar). As demais palavras assumiram o seu campo semântico correspondente de forma individual.
Os cálculos foram refeitos, considerando-se o agrupamento das palavras pelos seus respectivos sinônimos semânticos. Com base nos resultados dessa segunda análise, foi realizado um levantamento de quantas vezes essas palavras (após a lematização semântica) são evocadas em primeiro lugar (alto valor simbólico). Na sequência foram calculadas as proporções de alto valor simbólico $\left(P_{v s}\right)$, dividindo-se o número de ocorrências de cada palavra no primeiro rank das evocações $\left(F_{R}\right)$ por frequência total $\left(\mathrm{F}_{\mathrm{T}}\right)$ de cada corpus. Assim, a fórmula estabelecida por Wachelke (2009) seria $P_{v s}=F_{R} / F_{T}$. Na sequência o cálculo do INCEV é realizado pela divisão das ocorrências de alto valor simbólico $\left(F_{R}\right)$ pelo total de participantes da amostra $(N)$, obtendo-se um resultado que varia de 0 a 1. Logo, utiliza-se a fórmula INCEV $=F_{R} / N$. A Tabela 3 apresenta os resultados destes cálculos, no que se refere aos elementos evocados a partir do termo indutor "preparação para velhice".

Tabela 3. Índice de Centralidade dos Elementos das Representações Sociais sobre "Preparação para Velhice" em Situação Normal e de Substituição ( $N=72)$.

\begin{tabular}{|c|c|c|c|c|c|c|c|c|c|}
\hline \multicolumn{5}{|c|}{$\begin{array}{l}\text { Preparação para a velhice } \\
\text { (situação normal) }\end{array}$} & \multicolumn{5}{|c|}{$\begin{array}{l}\text { Preparação para a velhice } \\
\text { (situação de substituição) }\end{array}$} \\
\hline \multirow[b]{2}{*}{ Palavras } & \multicolumn{2}{|c|}{ Frequência } & \multirow[b]{2}{*}{$\mathbf{P}_{\text {vs }}$} & \multirow[b]{2}{*}{ INCEV } & \multirow[b]{2}{*}{ Palavras } & \multicolumn{2}{|c|}{ Frequência } & \multirow[b]{2}{*}{$\mathbf{P}_{\mathrm{vs}}$} & \multirow[b]{2}{*}{ INCEV } \\
\hline & $\begin{array}{c}f \\
\text { total }\end{array}$ & $\begin{array}{c}f \text { rank } \\
1\end{array}$ & & & & $\underset{\text { total }}{f}$ & $\begin{array}{c}\text { f rank } \\
1\end{array}$ & & \\
\hline Saúde & 23 & 12 & 0,52 & 0,16 & $\begin{array}{c}\text { Despreocupação desnecessária, não } \\
\text { pensa, está longe }\end{array}$ & 33 & 5 & 0,15 & 0,06 \\
\hline Família & 20 & 4 & 0,20 & 0,05 & Saúde & 21 & 9 & 0,42 & 0,12 \\
\hline Atividade e exercício & 16 & 2 & 0,12 & 0,02 & Não aceitação/Não se vê idoso & 16 & 5 & 0,31 & 0,06 \\
\hline Educação, informação e conhecimento & 15 & 5 & 0,33 & 0,06 & Família & 15 & 2 & 0,13 & 0,02 \\
\hline Despreparo & 8 & 4 & 0,50 & 0,05 & Desvalorização, desrespeito e desprezo & 14 & 4 & 0,28 & 0,05 \\
\hline Qualidade de vida & 8 & 3 & 0,37 & 0,04 & Despreparo & 13 & 3 & 0,23 & 0,04 \\
\hline Financeiro & 8 & 1 & 0,12 & 0,01 & Aposentadoria & 9 & 4 & 0,44 & 0,05 \\
\hline Preparação e prevenção & 8 & 2 & 0,25 & 0,02 & Financeiro & 7 & 2 & 0,28 & 0,02 \\
\hline Cuidado & 7 & 1 & 0,14 & 0,01 & Respeito & 5 & 2 & 0,40 & 0,02 \\
\hline Aceitação & 6 & 4 & 0,66 & 0,05 & Medo & 5 & 1 & 0,20 & 0,01 \\
\hline Doenças & 4 & 1 & 0,25 & 0,01 & Qualidade de vida & 5 & 3 & 0,60 & 0,04 \\
\hline Médico & 4 & 3 & 0,75 & 0,04 & Perda & 5 & 1 & 0,20 & 0,01 \\
\hline Amor & 4 & 2 & 0,50 & 0,02 & Amor & 5 & 2 & 0,40 & 0,02 \\
\hline Falta & 4 & 1 & 0,25 & 0,01 & Trabalho & 5 & 1 & 0,20 & 0,01 \\
\hline \multirow[t]{4}{*}{ Alegria } & 4 & 1 & 0,25 & 0,01 & Moradia & 4 & 2 & 0,50 & 0,02 \\
\hline & & & & & Educação & 4 & 1 & 0,25 & 0,01 \\
\hline & & & & & Conflitos familiares & 4 & 1 & 0,25 & 0,01 \\
\hline & & & & & Cuidado & 4 & 1 & 0,25 & 0,01 \\
\hline
\end{tabular}

Nota. Elaborada pelas autoras. Legenda: $f=$ frequência; $P_{v s}=$ proporções de alto valor simbólico; INCEV= índice de centralidade dos elementos evocados. 
A proporção de centralidade de um elemento central precisa ser maior que a metade (Pvs $\geq 0,51$ ). Os elementos com INCEV $\geq 0,10$ são considerados centrais. Os elementos que tiveram valores próximos a 0,10 no INCEV são considerados elementos periféricos salientes ou sobre ativados. Os demais, com valores bem abaixo do 0,10 , são elementos periféricos comuns (Wachelke, 2009).

Em relação ao termo indutor "Preparação para velhice", na situação normal confirmou-se a centralidade do elemento saúde e na situação de substituição este mesmo elemento não chegou a atingir a confirmação, mas aproximou-se, podendo ser considerado um elemento periférico sobre ativado. Os demais elementos apresentaram-se como periferias comuns. Os elementos periféricos comuns que mais se aproximaram do núcleo central na situação normal foram educação, informação e conhecimento, e na situação de substituição foram os termos não aceitação e não se vê idoso.

Portanto, a centralidade do elemento saúde foi confirmada somente na situação normal, sendo considerada como periferia sobre ativada na situação de substituição. Porém, a periferia comum apresenta a possibilidade de uma zona muda que negativiza a fase da velhice, por meio da dificuldade de aceitação que o processo de envelhecimento é inerente ao desenvolvimento de quaisquer indivíduos.

\section{Discussão}

A escola estrutural do pensamento social entende a representação social como um sistema de unidades cognitivas organizadas numa estrutura de conhecimento (Abric, 2003; Flament \& Rouquette, 2003). Descrever as representações sociais de conselheiros municipais do idoso sobre a preparação para velhice em termos estruturais, ao menos em sua essência, equivale a identificar os elementos que compõem o seu núcleo central. De tal modo, foi possível identificar que o elemento "saúde" apresentou maior intensidade de evocações, mas também se sugere que o mesmo esteja vinculado a "alimentação" e respectivamente a "qualidade de vida". Estes resultados corroboram com pesquisa que identificou representações sociais de idosos sobre cuidados de saúde centralizados em cuidados médicos e alimentares (Silva \& Menandro, 2014).

Embora se apresentem com menor frequência os elementos "despreparo", "educação", e "aceitação" também emergem como prováveis integrantes do núcleo central. Kalache (2008) explica que para garantir qualidade de vida na fase da velhice é preciso promover um envelhecimento saudável, ou seja, manter a capacidade funcional e prevenir deficiências durante o curso da vida. Contudo, ressalta que os decisores de políticas públicas precisam aceitar de modo positivo o envelhecimento da população, e prepararem-se para a necessidade de reformulação dos sistemas de educação, lazer e meios de comunicação para atender esta demanda.

Importa, ainda, identificar os elementos que compõem a zona muda, ou seja, os espaços de representações que embora sejam comuns no grupo pesquisado e nele partilhadas, não se revelam facilmente nos discursos diários e, ainda mais, na investigação coletado em situação normal, pois são consideradas como não adequadas em relação às normas sociais vigentes (Piermattéo, \& Guimelli, 2012). Foi possível observar que o elemento "saúde" novamente apresenta maior frequência, mas desta vez está acompanhado de estereótipos negativos sobre a preparação para velhice. A influência das normas sociais vigentes pode levar o indivíduo a expressar ideias positivas perante um objeto, mesmo que ele tenha construído implicitamente uma atitude negativa sobre este objeto (Flament et al., 2006). Neste sentido, a imagem negativa da velhice é fortemente marcada pela despreocupação e despreparação para esta fase da vida. Por outro lado, a preocupação com a aposentadoria também aponta como possível integrante do núcleo central no discurso implícito destes participantes. A partir das diferentes possibilidades, vale confirmar a centralidade do núcleo central sobre a preparação para a velhice.

Guimelli e Deschamps (2000) verificaram que alguns laços que mantém, um elemento em um conjunto aparece como um importante indicador pertinente à centralidade. Este fenômeno pode ser observado no elemento "saúde", que apresentou maior frequência nas duas situações de coleta (normal e de substituição). Apesar de ser possível confirmar a centralidade do elemento "saúde" somente na situação de coleta normal, na situação de substituição ele pode ser considerado um elemento periférico sobre ativado nas representações sociais dos participantes. Estes resultados corroboram com orientações das teorias do envelhecimento produtivo, bem-sucedido, vital, saudável e ativo, que apontam a saúde como um elemento determinante para a preparação para velhice (Fernández-Ballesteros et al, 2013; Miralles, 2011; Teixeira \& Neri, 2008; WHO, 2005). As políticas públicas nacionais e internacionais de proteção à pessoa idosa também trazem em suas legislações 
recomendações de fomento a saúde (Giacomin, 2013; WHO, 2005). Portanto, preocupações com os aspectos da saúde da população idosa são apresentadas nos âmbitos individual, científico, social e político.

Os elementos periféricos mais citados na análise prototípica nas duas situações de coleta de dados (normal e de substituição) foram: "família", "atividade", e financeiro. No entanto, notou-se que na situação normal a preparação para velhice está relacionada aos cuidados nos âmbitos, financeiro ou mesmo familiares, e ainda sugere-se que as atividades devem ser voltadas para o lazer. Enquanto que na situação de substituição estes mesmos elementos (família, financeiro e atividade) estão relacionados à despreocupação e a não aceitação. Nota-se que os cuidados com idoso tanto no senso comum, como no saber científico e nas legislações de proteção ao idoso cabe primeiramente à família (Giacomin, 2013; WHO, 2005).

No que diz respeito aos aspectos financeiros, pesquisas de âmbito internacional mencionam a preocupação de fornecer apoio financeiro a idosos em situação de vulnerabilidade social (Berthé et al, 2013; Song \& Chen, 2015; Torrado Ramos et al, 2014). No Brasil, discute-se a questão de abusos financeiros contra os idosos (W. C. Moreira et al, 2016) e as diretrizes do CMDI apontam a necessidade de captação de recursos financeiros para a causa dos idosos (Conselho Nacional dos Direitos do Idoso, 2016; Giacomin, 2013). Logo, pode-se inferir a possibilidade de uma zona muda na periferia das representações sociais sobre preparação para velhice pautada na despreocupação e não aceitação. Este último elemento foi confirmado na periferia comum do INCEV, juntamente com o elemento "não se vê idoso". Portanto, a periferia comum exibe uma provável zona muda que negativiza a fase da velhice, por meio da dificuldade de aceitação que o processo de envelhecimento é inerente ao desenvolvimento de quaisquer seres humano.

A zona de contraste apresenta elementos representacionais interlocutores, que embatem com o núcleo central, pois tentam entrar ou permanecer nele (Abric, 2003). De tal modo, percebe-se que os elementos educação, informação e conhecimento confirmados pelo INCEV como periferias comuns na situação normal, emergem como elementos de transição no núcleo central. Desde o Plano de Ação Internacional para o Envelhecimento, criado em Viena no ano de 1982 (World Health Organization, 2005) que a educação é recomendada como direito da população idosa, e ainda é um dos princípios do envelhecimento ativo, mas cabe ao idoso buscar oportunidades ofertadas por programas específicos para manutenção da sua saúde global.

Pesquisas de âmbito nacional apresentam inquietações sobre a efetivação e divulgação deste direito à educação, bem como da necessidade de se promover uma educação gerontológica para profissionais que lidam com a população idosa (Alves \& Vianna, 2010; Takahashi \& Alves, 2015). Portanto, pode-se inferir que embora o tema sobre o direito a educação esteja presente nos contextos normativos das sociedades, a falta de informação e conhecimento por parte dos maiores interessados (os idosos), provocam discussões sobre a falta de apoio para a efetivação deste direito.

Por outro lado, o vestígio da existência de uma zona muda nestas representações indica que o desrespeito com a fase da velhice, pode estar associado com o medo de enfrentamento das adversidades decorrentes desta fase da vida. No entanto são elementos que estão sendo discutidos, e que embatem com a representação de não aceitação da fase da velhice. Fernandes e Andrade (2016), explicam que fatores extrínsecos podem aumentar os efeitos negativos do envelhecimento. De tal modo, o desmascaramento destes estereótipos negativos pode possibilitar uma discussão mais explícita sobre o tema, e/ou ainda a construção de novas representações.

Por fim, são apresentados os elementos com menor possibilidade de vir a pertencer ao núcleo central (Abric, 2003). Vale destacar que o elemento "esporte" apresentou maior ordem de importância na situação normal. Este resultado remete ao ideal de idoso ativo, mas a probabilidade de uma zona muda das representações sociais apresenta o elemento "solidão", associado à preparação para velhice. Neste momento, também cabe à reflexão sobre os elementos representacionais compartilhados por um menor número de participantes e menos valorizados pelos mesmos. Estes são os casos dos elementos "frequentar" e "participar" na situação normal; e do elemento "consciência" na situação de substituição.

\section{Considerações finais}

O presente estudo buscou identificar como se organiza as representações sociais e os possíveis elementos que compõem a zona muda de conselheiros municipais do idoso sobre a preparação para velhice. Os resultados permitiram identificar que as representações sociais desses atores sobre a preparação para velhice 
organizam-se da seguinte forma: destacam-se no núcleo central representações sociais normativas sobre enveIhecimento saudável e/ou com qualidade de vida.

$\mathrm{Na}$ primeira periferia prevaleceu à preocupação com cuidados nos âmbitos financeiro ou mesmo familiares, além da prática de atividades destinadas ao lazer. Na zona de contraste destacou-se que a problematização da falta de informação e conhecimento sobre as questões direcionadas para o público idoso, provocam a falta de apoio para a efetivação dos seus direitos. A segunda periferia apresenta que a representação do idoso ativo está longe de pertencer ao núcleo central.

Em relação à possibilidade de uma zona muda destas representações foi possível identificar elementos contranormativos a partir da seguinte organização: no núcleo central destaca-se novamente o elemento "saúde", mas desta vez associado a estereótipos negativos de despreocupação e despreparação para a velhice. A primeira periferia também negativa a velhice, pois repete os mesmos elementos da situação normal (família, financeiro e atividade), mas relaciona-os a despreocupação e a não aceitação. Na zona de contraste destaca-se que o desrespeito, associado ao medo são possíveis elementos que embatem com a representação negativa da velhice. A segunda periferia apresenta que a conscientização sobre as questões que estigmatizam a velhice, como por exemplo, as perdas, o isolamento e o desprezo estão longe de pertencer ao núcleo central das representações sociais.

Confirmou-se a centralidade do elemento "saúde" na situação normal e na situação de substituição o mesmo foi considerado um elemento periférico sobre ativado das representações sociais dos participantes do estudo. Na periferia comum destacou-se a possibilidade de uma zona muda que negativiza, não aceita e não reconhece o próprio envelhecimento.

Os resultados analisados no presente estudo podem e devem ser identificados como situados e específicos do contexto pesquisado. Embora também possam favorecer a compreensão das proposições das ações do poder público junto com a sociedade civil direcionado as políticas públicas para a população idosa.

Concluindo-se, pode-se inferir que embora as representações sociais sobre a preparação para velhice estejam pautadas nos discursos normativos entendidos pelas legislações vigentes, e consequentemente socialmente aceitos, a possibilidade de uma zona muda indica estereótipos negativos relacionados à estigmatização da velhice.
As limitações desse estudo decorreram principalmente pela dificuldade em contatar todos os integrantes atuantes no conselho. Isto ocorreu devido ao fato dos mesmos terem outras atribuições além do conselho, o que acarreta na impossibilidade de comparecimento nas reuniões plenárias. De qualquer modo, os resultados deste estudo podem contribuir na compreensão do cenário de elaboração e efetivação de políticas públicas para a população idosa em âmbito nacional.

A partir de tais reflexões sugerem-se pesquisas sobre reflexões que possibilitem modificar a visão estereotipada e negativa da velhice, e consequentemente abrir caminhos para que toda a população se conscientize da importância e necessidade de prepararem-se nos âmbitos individual e social para a fase da velhice.

\section{Referências}

Abric, J. C. (2001). O estudo experimental das representações sociais In D. Jodelet (Org.), As representações sociais (pp. 155-171). Rio de Janeiro: UERJ.

Abric, J. C. (2003). La recherche du noyau central et de la zone muette des représentations sociales. In J. C. Abric (Org.), Méthodes d'étude des représentations sociales (pp. 59-80). Ramonville Sant-Agne, France: ERES.

Aird, R. L., \& Buys, L. (2015). Active aging: Exploration into self-ratings of "being active," out-of-home physical activity, and participation among older Australian adults living in four different settings. Journal of Aging Research, 2015: 501823. doi: 10.1155/2015/501823

Alves, V. P., \& Vianna, L. G. (2010). Políticas públicas para a educação gerontológica na perspectiva da inserção social do idoso: desafios e possibilidades. Ensaio: Avaliação e Políticas Públicas em Educação, 18(68), 489-510. doi: 10.1590/S0104-40362010000300005

Berthé, A., Berthé-Sanou, L., Konaté, B., Hien, H., Tou, F., Drabo, M., \& Macq, J. (2013). Les personnes âgées en Afrique subsaharienne: une population vulnérable, trop souvent négligée dans les politiques publiques. Santé Publique, 25(3), 367-371. doi: 10.3917/spub.253.0367

Braconier, H. (2010). Coping with the job crisis and preparing for ageing: The case of Finland. OECD Economic Department Working Papers, (777), 0-1. doi: 10.1787/5kmddq4vnwvc-en

Camargo, B. V., \& Justo, A. M. (2016). Tutorial para uso do software de análise textual IRAMUTEQ. Florianópolis, SC: Universidade Federal de Santa Catarina. Recuperado de http://www.iramuteq.org/ documentation/fichiers/Tutorial\%20IRaMuTeQ\%20em\%20portugues_17.03.2016.pdf

Conselho Nacional dos Direitos do Idoso (Org.) (2016). Protagonismo e empoderamento da pessoa idosa - por um Brasil de todas as idades. 4ª - Conferência Nacional de Direitos da Pessoa Idosa, Brasília, DF. Recuperado de http://www.sdh.gov.br/assuntos/conferenciasdh/4a-conferencia-nacional-dos-direitos-da-pessoa-idosa

Costa, T. L. D., Oliveira, D. C. D., \& Formozo, G. A. (2012). Representações sociais sobre pessoas com HIV/AIDS entre enfermeiros: uma análise estrutural e de zona muda. Estudos e Pesquisas em Psicologia, 12(1), 242-259. doi: 10.12957/epp.2012.8318

Fernandes, J. S. G., \& Andrade, M. S. (2016). Representações sociais de idosos sobre velhice. Arquivos Brasileiros de Psicologia, 68(2), 48-59. Recuperado de http://www.redalyc.org/articulo. oa? $\mathrm{id}=229048487005$ 
Representações de conselheiros do idoso sobre preparação para velhice

Fernandes, J. S. G., Costa, B. H. R., \& Andrade, M. S. (2017). Representaciones sociales de adultos mayores sobre la familia. Ciencias Psicológicas, 11(1), 41-48. doi: 10.22235/cp.v11i2.1345

Fernández-Ballesteros, R., Robine, J. M., Walker, A., \& Kalache, A. (2013). Active aging: A global goal. Current Gerontology and Geriatrics Research. 2013: 298012. doi: 10.1155/2013/298012

Flament, C., Guimelli, C., \& Abric, J. C. (2006). Effets de masquage dans l'expression d'une représentation sociale. Les Cahiers Internationaux de Psychologie Sociale, 1, 15-31. doi: 10.3917/cips.069.0015

Flament, C., \& Rouquette, M. L. (2003). Anatomie des idées ordinaire: comment étudier les représentations sociales. Paris: Armand Colin.

Freitas, M. C., Campos, T. D., \& Gil, C. A. (2017). Expectativas e concepções de trabalho na velhice em homens na meia-idade. Estudos Interdisciplinares em Psicologia, 8(2), 43-64. doi: 10.5433/2236-6407.2017v8n2p43

Giacomin, K. C. (2013). Panorama dos 10 anos do CNDI. In N. P Muller \& A. Parada (Orgs.), Dez anos do Conselho Nacional dos Direitos dos Idosos: repertórios e implicações de um processo democrático (pp. 167-190). Brasília, DF: Secretaria de Direitos Humanos da Presidência da República.

Guimelli, C., \& Deschamps, J. C. (2000). Effets de contexte sur la production d'associations verbales: le cas des représentations sociales des Gitans. Cahiers Internationaux de Psychologie Sociale, 47(48), 44-54. Recuperado de http://psycnet.apa.org/record/2000-12644-003

Hinrichs, K. (2016). Pension reforms in Europe: Directions and consequences. In K. Hinrichs (Org.), Converging Europe (pp. 109-132). Londres: Routledge.

Kalache, A. (2008). O mundo envelhece: é imperativo criar um pacto de solidariedade social. Ciência \& Saúde Coletiva, 13(4), 1107-1111. doi: 10.1590/S1413-81232008000400002

Lee, Y. J., \& Xiao, Z. (1998). Children's Support for Elderly Parents in Urban and Rural China: Results from a National Survey. Journal of Cross-Cultural Gerontology, 13, 39-62. doi: 10.1023/A:1006591608724

Miralles, I. (2011). Envejecimiento productivo: las contribuciones de las personas mayores desde la cotidianidad. Trabajo y Sociedad, (16), 137-161. Recuperado de http://www.scielo.org.ar/scielo.php?scrip$\mathrm{t}=$ sci_arttext\&pid=S1514-68712011000100009\&lng=es\&tlng=es

Moreira, J. O., \& Vieira, R. F. (2014). Permanência no emprego: velhice saudável ou negação do envelhecimento?. Revista Pesquisas e Práticas Psicossociais, 9(1), 57-63. Recuperado de http://seer.ufsj.edu.br/ index.php/revista_ppp/article/view/834/642

Moreira, W. C., Damasceno, C. K. C. S., Vieira, S. K. S. F., Campêlo, T. P.T., Campêlo, D. S., \& Alencar, D. D. C. (2016). Análise sobre as políticas públicas de enfrentamento a violência contra o idoso. Revista de Enfermagem UFPE (online), 10(4), 1324-1331. doi: 10.5205/reuol.8464-74011-1-SM.1004201621

Moscovici, S. (2012). Representações sociais: investigações em psicologia social. Petrópolis: Vozes.

Pena, M. P., Urdapilleta, I., Tavani, J. L., Pruzina, I., \& Verhiac, J. F. (2016). Représentations sociales de la personne obèse et de l'obésité: effets de la situation de contact. Psychologie Française, 61(3), 235-250. doi: 10.1016/j.psfr.2015.05.003

Piermattéo, A., \& Guimelli, C. (2012). Expression de la zone muette des représentations sociales en situation d'entretien et structure discursive: une étude exploratoire. Les Cahiers Internationaux de Psychologie Sociale, 94(1), 21-45. doi: 10.3917/cips.094.0223

Silva, S. P. C., \& Menandro, M. C. S. (2014). As representações sociais da saúde e de seus cuidados para homens e mulheres idosos. Saúde e Sociedade, 23(2), 626-640. doi: 10.1590/S0104-12902014000200022

Song, P., \& Chen, Y. (2015). Public policy response, aging in place, and big data platforms: Creating an effective collaborative system to cope with aging of the population. Bioscience Trends, 9(1), 1-6. doi: 10.5582/ bst.2015.01025

Takahashi, F. G. M., \& Alves, V. P. (2015). Imagens representacionais das políticas públicas à educação e à saúde, no imaginário de um grupo de idosos da comunidade Quilombola-Kalunga, de Monte Alegre de Goiás. Revista Ensaio: Avaliação e Políticas Públicas em Educação, 23(88), 567-592. doi:10.1590/S0104-40362015000300002

Teixeira, I. N. D., \& Neri, A. L. (2008). Envelhecimento bem-sucedido: uma meta no curso da vida. Psicologia USP, 19(1), 81-94. doi: 10.1590/S0103-65642008000100010

Torrado Ramos, A. M., Sánchez Pérez, L., Somonte López, R., Cabrera Marsden, A. M., Henríquez Pino Santos, P. C., \& Lorenzo Pérez, O. (2014). Envejecimiento poblacional: una mirada desde los programas y políticas públicas de América Latina, Europa y Asia. Revista Novedades en Población, 10(19), 18-29. Recuperado de http://scielo. sld.cu/pdf/rnp/v10n19/rnp020114.pdf

Torres, T. L., Camargo, B. V., Boulsfield, A. B., \& Silva, A. O. (2015) Representações sociais e crenças normativas sobre envelhecimento. Ciência \& Saúde Coletiva, 20(12), 3621-3630. doi: 10.1590/1413-812320152012.01042015

Wachelke, J. F. R. (2009). Índice de centralidade de representações sociais a partir de evocações (INCEV): exemplo de aplicação no estudo da representação social sobre envelhecimento. Psicologia: Reflexão e Crítica, 22(1), 102-110. doi: 10.1590/S0102-79722009000100014

Wachelke, J. F. R., \& Wolter, R. (2011). Critérios de construção e relato da análise prototípica para representações sociais. Psicologia: Teoria e Pesquisa, 27(4), 521-526. doi: 10.1590/S0102-37722011000400017

Wolter, R. P., \& Wachelke, J. (2013). Índices complementares para o estudo de uma representação social a partir de evocações livres: raridade, diversidade e comunidade. Psicologia: Teoria e Prática, 15(2), 119-129. Recuperado de https://www.researchgate.net/publication/256486953

World Health Organization. (2005). Envelhecimento ativo: uma política de saúde (S. Gontijo, Trad.). Brasília: Organização Pan-Americana da Saúde. Recuperado de http://bvsms.saude.gov.br/bvs/publicacoes/ envelhecimento_ativo.pdf

Zaidi, A. (2008). Features and challenge of population ageing: The European perspective. Policy Brief March, 1. Recuperado de http://envejecimiento.csic.es/documentos/documentos/europeancentre-features-01.pdf 
Janaína da Silva Gonçalves Fernandes, Doutora em Psicologia Educacional pelo Centro Universitário FIEO (UNIFIEO), é Professora

do Programa de Pós-graduação em Psicologia Educacional

do Centro Universitário FIEO (UNIFIEO). Endereço para correspondência: Av. Franz Voegeli, 300, Vila Yara, Osasco, SP, Brasil, CEP 06020-190. E-mails: janainagoncalves80@yahoo.com.br e/ou janaina.fernandes@unifieo.br

Márcia Siqueira de Andrade, Doutora em Psicologia da Educação pela Pontifícia Universidade Católica de São Paulo (PUC-SP), é Professora do Programa de Pós-graduação em Psicologia Educacional do Centro Universitário FIEO - (UNIFIEO). E-mails: marciandrade.ilapp@gmail.com e/ou mandrade@unifieo.br

Recebido em 11.Nov.17 Revisado em 14.Mai.18

Aceito em 13.Ago.18 